\title{
Natural cold pressed oils as cosmetic products
}

\author{
MAŁGORZATA LIGĘZA"A-F, DOMINIKA WYGLĄDACZ1, A-F, ALEKSANDRA TOBIASZ1, A-F, \\ KAMILA JAWORECKA ${ }^{1, A-F}$, ADAM REICH ${ }^{2, A}$, C-G \\ ${ }^{1}$ Student Research Group of Experimental Dermatology, Institute and Department of Dermatology, \\ Venereology and Allergology, Wroclaw Medical University \\ ${ }^{2}$ Institute and Department of Dermatology, Venereology and Allergology, Wroclaw Medical University
}

A - Study Design, B - Data Collection, C - Statistical Analysis, D - Data Interpretation, E - Manuscript Preparation, $\mathbf{F}$ - Literature Search, $\mathbf{G}$ - Funds Collection

Summary Background. It seems that patients may ask general practitioners about natural cosmetics applied on the skin regarding their safety and suitability.

Objectives. The aim of the study was to analyze natural cold pressed oils as potential cosmetic products.

Material and methods. Cold pressed oils obtained from selected seeds and fruit stones were analyzed, including: chokeberry seed oil, blackcurrant seed oil, elderberry seed oil, raspberry seed oil, apricot seed oil, tomato seed oil, strawberry seed oil, broccoli seed oil, Nigella sativa seed oil, hemp oil, safflower seed oil, Silybum marianum seed oil and coconut oil. 80 adult volunteers assessed the cosmetic properties of the analyzed oils. Each of the volunteers tested 2 to 4 different oils, by applying them on the skin. In addition, patch tests with all analyzed oils were performed on 23 individuals.

Results. The majority of tested oils were positively evaluated by the participants: in the opinion of the participants, oil extracted from safflower had the best appearance ( $100 \%$ positive opinions), coconut oil had the best smell ( $70 \%$ positive opinions), while black currant seed oil showed the best absorbency (85\% positive opinions). No irritation was observed within the analyzed product group, albeit one allergic reaction to apricot seed oil was observed with patch testing.

Conclusions. Based on the achieved results, it could be suggested that natural cold pressed oils can be applied to the skin as cosmetics. Our observations may be helpful for general practitioners when choosing natural cosmetics.

Key words: plant oils, vegetable oils, patch tests, contact eczema, cosmetics.

Ligęza M, Wyglądacz D, Tobiasz A, Jaworecka K, Reich A. Natural cold pressed oils as cosmetic products. Fam Med Prim Care Rev 2016; 18(4): 443-447, doi: 10.5114/fmpcr.2016.63699.

\section{Background}

Recently, so-called ecological and natural products have become more and more popular. Undoubtedly, this is due to the increased number of reports on the harmful effects of various commonly used chemical substances on human body. This makes individuals search for cosmetics produced in a natural way, containing the smallest possible number of artificial additives [1]. Patients often ask their general practitioner for advice, so it is important that physicians are familiar with the subject. Medical references are reliable information sources, as they provide articles which objectively refer to natural products. Vegetable oils are relatively new on the cosmetic market. Previously they were used for consumption, but now they are more and more often applied in skin care.

\section{Objectives}

The subject of the study was to demonstrate that cold pressed oils of natural origin may be used as cosmetic products.

\section{Material and methods}

In the application study, the following cold pressed oils were used: chokeberry seed oil (Aronia melanocarpa (Michx.) Elliott), blackcurrant (Ribes nigrum L.), elderberry
(Sambucus nigra L.), raspberry (Rubus idaeus L.), apricot (Prunus armeniaca L.), tomato (Lycopersicon sp. Mill.), strawberry (Fragaria $x$ ananassa Duchesne), broccoli seed (Brassica oleracea L. var. italica Plenck), black cumin (Nigella sativa L.), hemp (Cannabis sativa L.), safflower (Carthamus tinctorius L.), milk thistle (Silybum marianum (L.) Gaertn) and coconut (Cocos nucifera L.). With the exception of coconut oil, which has a solid consistency, all other oils were liquid and were stored in a dark glass container measuring $15 \mathrm{~mL}$ of volume, and with special applicator.

All the tested oils were evaluated in order to examine possible allergenic (contact allergy) and irritating effects. For this purpose, the authors sought healthy volunteers, taking into consideration that the group should be diverse in terms of age and sex. This part of the experiment was conducted on 23 healthy individuals (12 women and 11 men from 18 to 60 years of age, median 39 years) with patch testing with all evaluated oils. A small amount of the tested oil was placed on blotting paper, and this paper was adhered under occlusion to the skin of the back. After 48 hours, all the blotting papers were removed, and the skin as evaluated for local reaction. A subsequent analysis was performed by one of the co-authors with appropriate experience in allergy diagnostics (AR) 48 hours later. Based on the two analyses, it was evaluated whether the particular substance caused irritation or a contact allergic reaction at the site of application [2].

The application study was conducted on 80 volunteers of both sexes (64 women and 16 men) from 18 to 65 years of age (median 41.5). Each person received 2 to 4 oil types 
for testing. The oils were manufactured by the company OleoWita (Milicz). This part of the study was performed by application of every cosmetic to the skin of the hand for at least 3 days. When the application of each product was finished, every participant filled out a survey, where he assessed the appearance, color, aroma, absorbability, spreadability and the consistency of the sample. There was also space to add additional comments on the applied products. The entire study was approved by the Bioethical Committee of the Medical University in Wrocław (agreement No. KB-284/2014). The obtained results were statistically analyzed using the Statistica ${ }^{\circledR} 10.0$ (StatSoft, Kraków) program. The results were considered significant if probability $p$ of the first type error was below 0.05 .

\section{Results}

\section{Patch tests}

During study with the patch test, only one allergic contact reaction was observed after administration of apricot seed oil (4.3\%). In the group of 23 evaluated individuals, there were no contact allergic reactions or irritation in response to all other tested oils.

\section{Application study}

Most of the tested preparations were evaluated as positive by the tested individuals. The respondents assessed the appearance of the tested oils as good. Safflower oil had the best rating $-100 \%$ of respondents rated its appearance as good or very good $(p<0.001)$. Details on assessment of the appearance of other oils are presented in Figure 1.

Rating of the appearance of the tested oil was closely related to its color. The color of elderberry seed oil received the lowest score, and $65 \%$ of the respondents described it as "dark". Blackcurrant seed oil, which $80 \%$ rated as "dark", received only 55\% positive ratings for appearance. In contrast, the color of safflower oil, which received the best ratings in terms of appearance, was described as "light" or "colorless". On the other hand, coconut oil, which was described as "light" or "transparent", received 90\% positive ratings in this category. The color of oils was described as "homogeneous" by a vast majority of the respondents. Only blackcurrant seed oil and broccoli seed oil were rated as "inhomogeneous" (10\% and 5\% of respondents, respectively) $(p<0.001)$ (Fig. 2).

The aroma of coconut oil received the best rating $(70 \%$ positive ratings, including $50 \%$ of respondents who rated
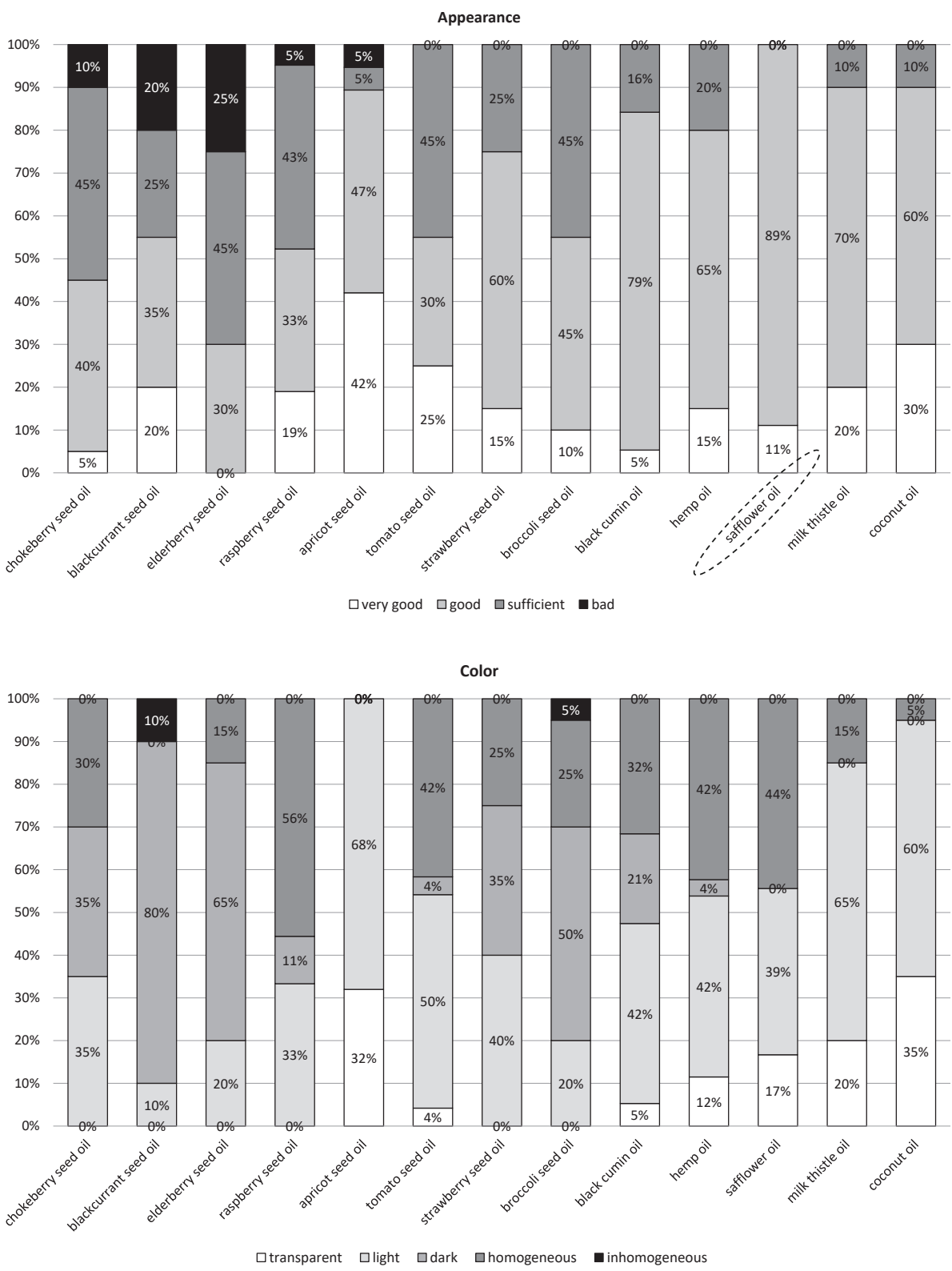

Figure 1. Appearance evaluation results of cold-pressed oils conducted by the testers (the name of the most appealing oil was circled)
Figure 2. Color evaluation results of cold-pressed oils conducted by the testers 
the aroma as "very pleasant") and apricot seed oil (64\% positive ratings). Safflower oil, thistle oil and broccoli seed oil received the most neutral ratings ("neutral aroma" or "no aroma") $(88 \%, 75 \%$ and $70 \%$ respectively) $(p<0.001)$. Most of the respondents did not like elderberry seed oil (65\% described it as "unpleasant") and blackcurrant seed oil (55\% negative opinions) $(p<0.001)$ (Fig. 3).

Most of the participants of the study positively rated the absorbability of the tested oils. The most positive ratings (absorbability assessed as "good" and "very good") were received by blackcurrant seed oil (85\%), strawberry seed oil $(85 \%)$ and apricot seed oil (84\%). On the other hand, 30\% of respondents rated coconut oil and tomato seed oil as "absorbing with certain difficulties" (Fig. 4). However, the detected differences were not statistically significant $(p=0.14)$.

The spreadability of the oils also received positive ratings. Raspberry seed oil, apricot seed oil, safflower oil and hemp oil received $100 \%$ positive ratings (spreadability assessed as "good" and "very good"). Only the black cumin oil was rated by $5 \%$ of respondents as "not spreadable" $(p<0.01)$ (Fig. 5).

Most of the respondents rated the consistency of tested oils as "moderately liquid". Tomato seed oil was rated as having the best consistency $(60 \%$ of respondents rated the consistency of this oil as "light" or "very light"), whereas coconut oil received the worst rating in this category, as $25 \%$ of respondents described its consistency as "thick" $(p=0.002)$ (Fig. 6).

In the additional survey, participants emphasized an improvement in skin condition after administration of the tested oils. The skin was described as smoother and well moisturized. None of the participants of this part of the study reported irritation or an allergic reaction.

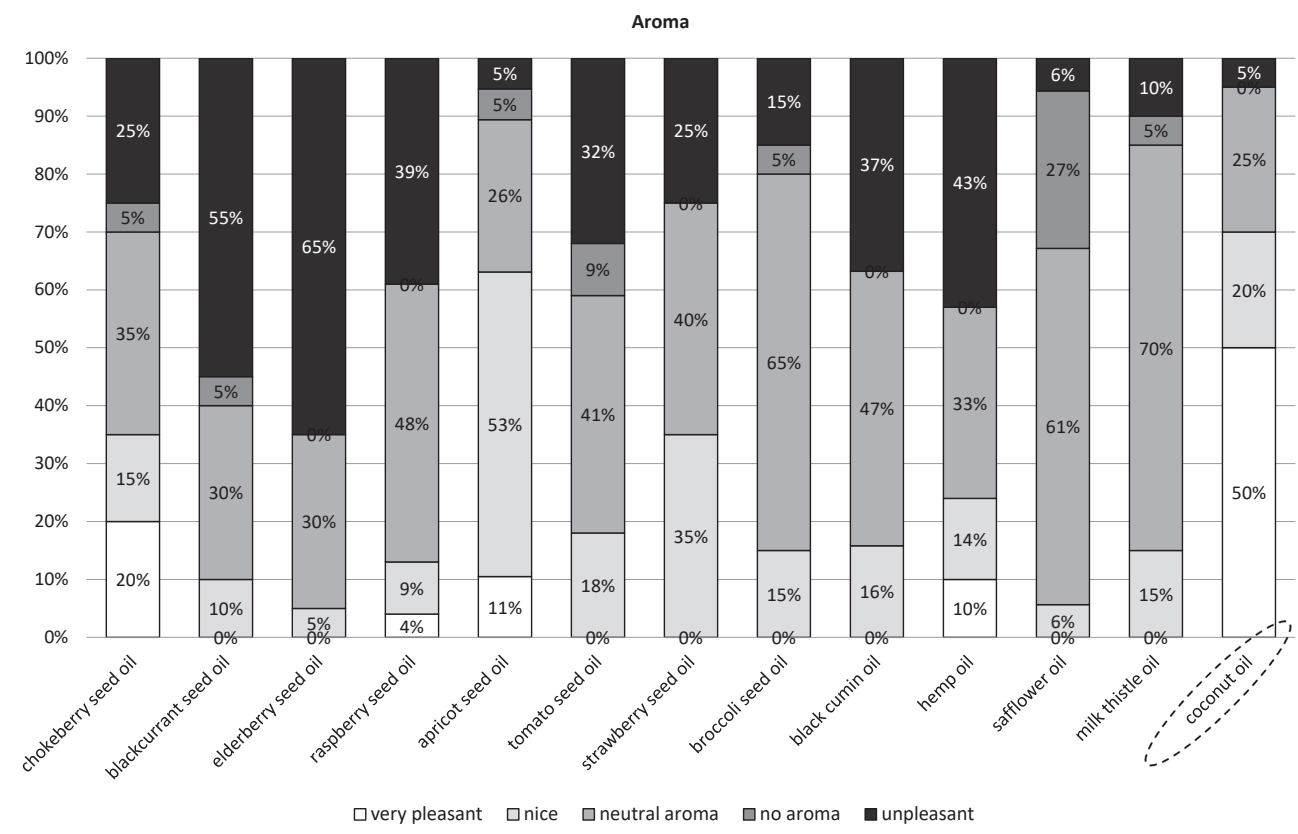

Figure 3. Aroma evaluation results of cold-pressed oils conducted by the testers (the name of the oil with the most appealing smell was circled)

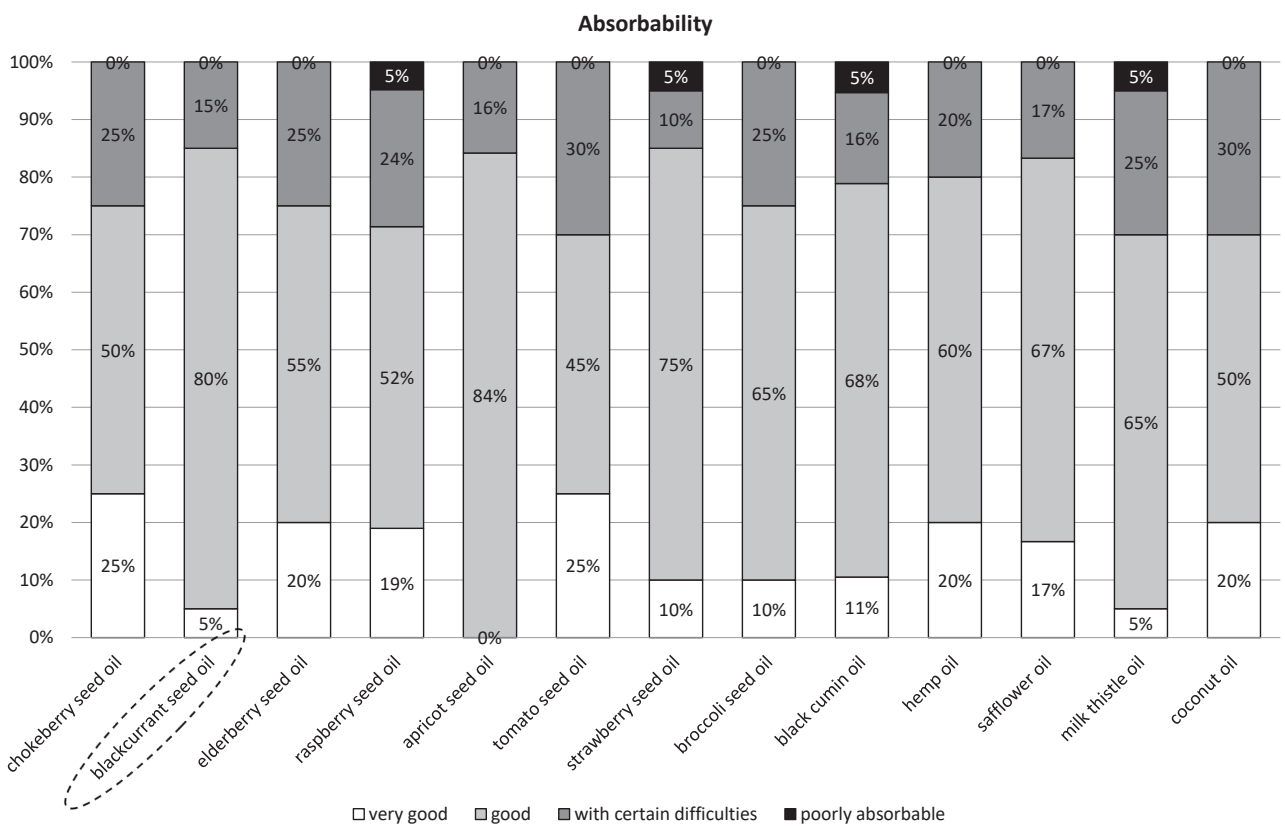

Figure 4. Absorbability rating of the tested cold pressed oils (the best rated oil is indicated) 


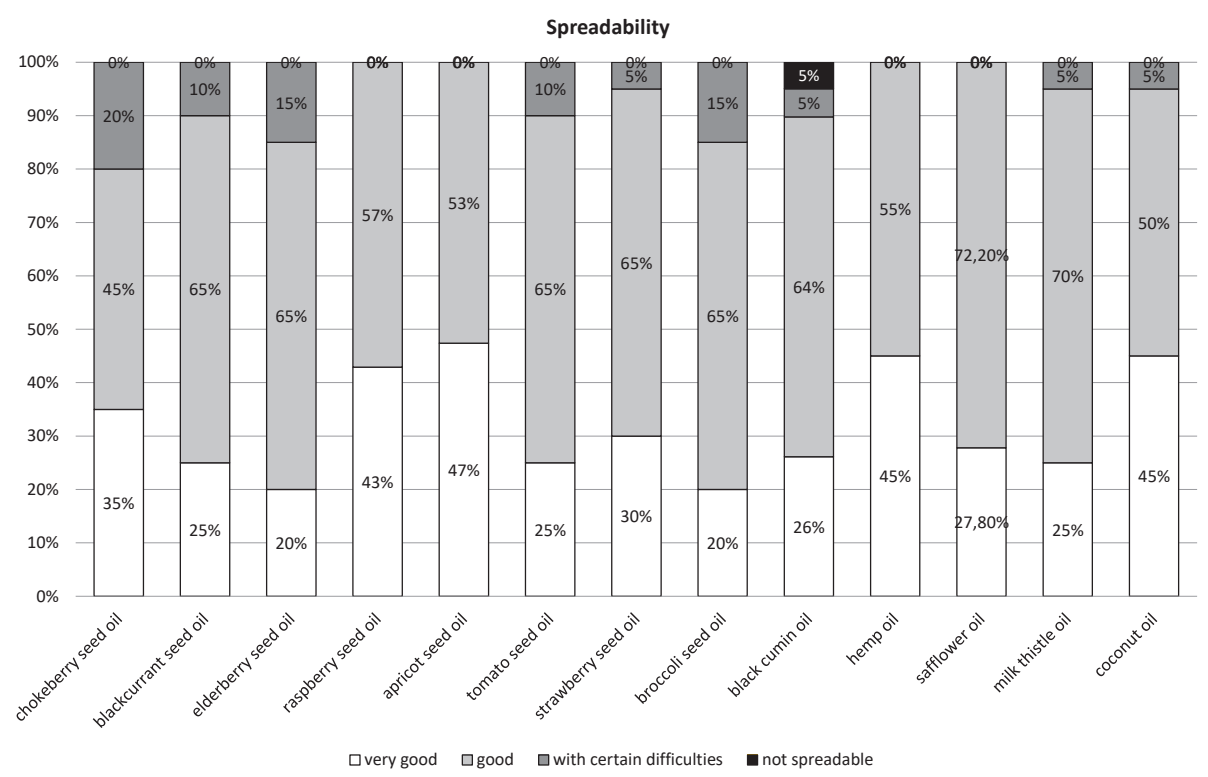

Figure 5. Rating of the spreadability of the tested cold pressed oils done by the testers

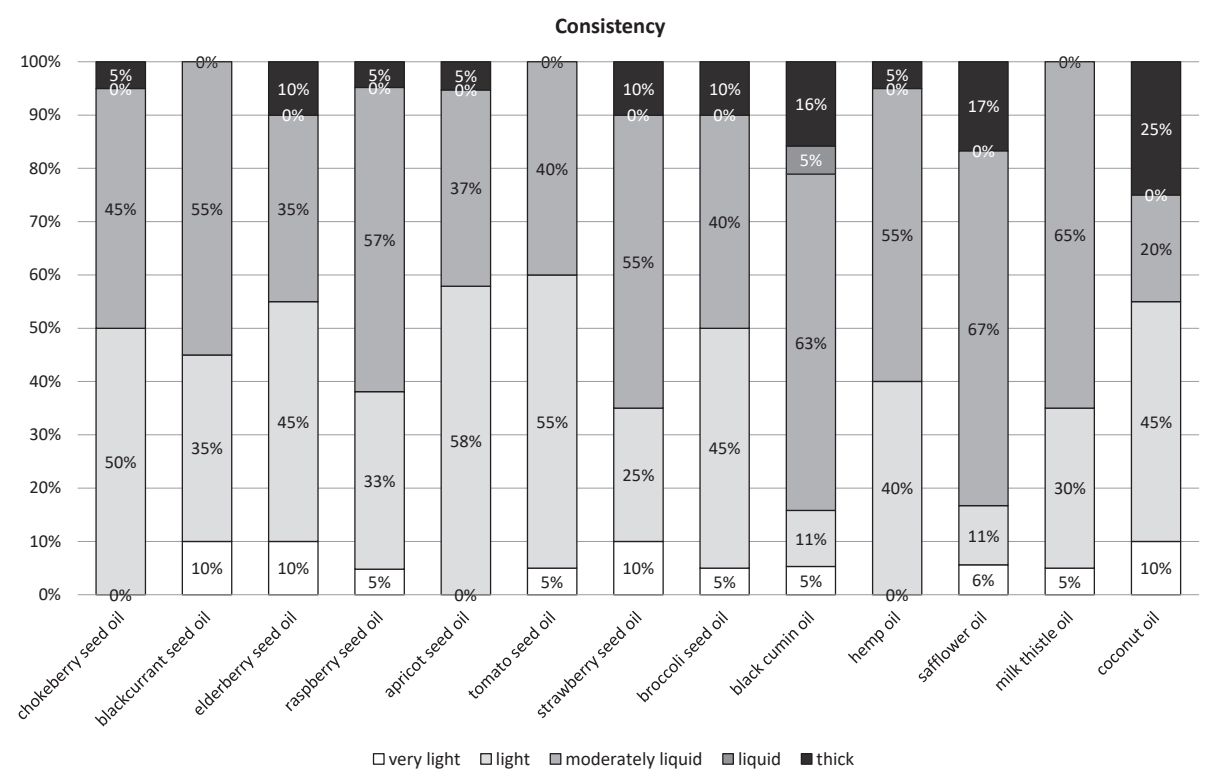

Figure 6. Rating of the texture of the tested cold pressed oils

\section{Discussion}

The individuals testing natural cold pressed oils rated their properties as good in terms of aroma, appearance, consistency, spreadability and absorbability. A large part of the respondents also pointed out the beneficial effect on skin condition, although evaluation of this effect was not the main aim of the study. The low number of ingredients used for manufacturing is an advantage of natural oils, because these oils usually do not contain standard ingredients of commonly available cosmetics, such as silicones, parabens or preservatives. However, it should be noted that natural oils may have some allergic potential due to the admixture of the protein fraction of the plants used to produce cosmetics. The allergic potential of this type of products depends mostly on their purification; however, even highly purified oils may comprise plant allergens [3]. It should be mentioned that commercially available tests with standardized plant allergens may not be representative for detection of most contact allergies due to the fact that natural products contain a variety of components, whereas patch tests with oil samples may be a reliable source of information [3]. In this study, the patch tests did not prove that the tested oils have high allergic potential; however, it should be mentioned that relatively few people were enrolled in the study, as well as all of them were healthy. Therefore, the results obtained in this study should be considered as preliminary. However, people with skin conditions, especially allergic diseases (patients with eczema, atopic dermatitis), should be very careful when using natural oils, as well as in the case of children, as these products were not tested on minors. Individuals who have a history of allergic reactions to plant derivatives should not use this type of natural cosmetics [4-6]. Further studies should also be performed in order to evaluate the allergic potential of the tested products on people with sensitive and atopic skin.

It should be also mentioned that the tested oils did not contain preservatives. On one hand, this reduces the risk of contact allergy to preservatives, on the other - it can significantly shorten the shelf life of this type of cosmetics. Natural antibacterial and antifungal products may be an alternative 
here [7]. Considering that patients have broad access to general practitioners, it seems that these doctors may be the first individuals whom patients will inquire about the legitimacy of using natural cosmetics. Any decision as to whether or not to recommend this type of cosmetics should be made carefully after considering all the possible advantages and disadvantages of natural skin care products [8].

The cold pressed oils tested in the present study may be qualified as natural cosmetics, because according to the definition established by the European Scientific Cooperative on Phytotherapy, "a natural cosmetic is a product which is embellished and nurtured by natural substances, friendly to the skin and environment, conducive to health, supporting self-regulation of the body, and preserving the natural beauty and harmonious development of the body and soul for a long time" [9]. According to the Kline report, the cosmetics market has enjoyed steady growth. Even in times of global crisis, the sale of eco-cosmetics constantly increases, while other markets experience decline [10]. Due to this eco-trend, a group of consumers described as LOHAS (Lifestyle of Health and Sustainability) has been distinguished. These are the people who lead a healthy and ecologically well-balanced lifestyle.
Due to the fact that there are many cosmetics on the market that are described as natural, it is necessary to introduce detailed regulations on conditions of production and the composition of natural and ecological products [9]. Therefore, ecological cosmetics must contain at least 95\% natural ingredients, they cannot contain synthetic fragrances and colorants, and synthetic fats, oils, silicones, parabens, paraffin, PEG emulsifiers and genetically modified substances must be prohibited [11]. The final products cannot be tested on animals, and the production process should be environmentally friendly [11].

It appears that cold pressed oils may be applied to the undamaged skin of adults, they do not present an irritating effect, and they only occasionally produce an allergic reaction. It seems that these findings may help general practitioners in the selection of appropriate natural cosmetics.

\section{Conclusions}

Taking into consideration the obtained results, cold pressed vegetable oils can be used as cosmetics. Furthermore, they do not have an irritating effect and only rarely cause allergic reactions.

Source of funding: The study was funded by the Lower Silesia Innovation Voucher at 329/B/2014 co-financed by the European Union from the European Social Fund under Sub-measure 8.2.1 of the Human Capital Operational Programme.

Conflict of interest: The authors declare no conflict of interests.

\section{References}

1. Łabędzka-Gardy M, Koza M. Naturalny kolagen występujący w organizmie człowieka oraz jego zastosowanie w kosmetyce i medycynie. Fam Med Prim Care Rev 2011; 12(3): 607-610.

2. Devos SA, Van Der Valk PG. Epicutaneous patch testing. Eur J Dermatol 2002; 12(5): 506-513.

3. Corazza M, Borghi A, Gallo R, et al. Topical botanically derived products: use, skin reactions, and usefulness of patch tests. A multicentre Italian study. Contact Dermatitis 2014; 70(2): 90-97.

4. Crawford GH, Sciacca JR, James WD. Tea tree oil: cutaneous effects of the extracted oil of Melaleuca alternifolia. Dermatitis 2004; 15(2): 59-66.

5. Simpson EL, Law SV, Storrs FJ. Prevalence of botanical extract allergy in patients with contact dermatitis. Dermatitis 2004; 15(2): 67-72.

6. Paulsen E, Chistensen LP, Andersen KE. Cosmetics and herbal remedies with Compositae plant extracts - are they tolerated by Compositae-allergic patients? Contact Dermatitis 2008; 58(1): 15-23.

7. Varvaresou A, Papageorgiou S, Tsirivas E, et al. Self-preserving cosmetics. Int J Cosmet Sci 2009; 31(3): 163-175.

8. González-Muńoz P, Conde-Salazar L, Vańó-Galván S. Allergic contact dermatitis caused by cosmetic products. Actas Dermosifiliogr 2014; 105(9): 822-832.

9. Mirkowska B. Eko-pielęgnacja - kosmetyki organiczne, naturalne - czyli jakie? Świat Przem Kosmet 2012; 3: 8-13.

10. Kline's cosmetics and toiletries USA study celebrates a golden jubilee [cited 03.06.2015]. Avaible from URL: http://www. klinegroup.com/news/cosmetics toiletries11-07-13.asp.

11. Natural and organic cosmetics [cited 03.06.2015]. Avaible from URL: http://www.ecocert.com/en/natural-and-organic-cosmetics.

Tables: 0

Figures: 6

References: 11

Received: 17.05.2015

Revised: 25.06.2015

Accepted: 18.09.2015

Address for correspondence:

Adam Reich, MD, PhD, Assoc. Prof.

Katedra i Klinika Dermatologii,

Wenerologii i Alergologii UM

ul. Chałubińskiego 1

50-368 Wrocław

Polska

Tel.: +48 71 784-22-92

E-mail: adam.reich@umed.wroc.pl 